\title{
A FAUNA MARAJOARA EM NARRATIVAS DE VIAJANTES DO SÉCULO XIX
}

\author{
Lucas Monteiro de Araújo ${ }^{1}$ \\ Agenor Sarraf Pacheco ${ }^{2}$
}

\section{Palavras Iniciais}

A região Amazônica foi, durante o século XIX, foco de devotados estudos sobre sua fauna, flora, vilas, patrimônios, habitantes, modos de vida, saberes e fazeres locais, por parte de diversos profissionais que por ela incursionaram e registraram suas impressões em publicações nacionais e internacionais.

Estes profissionais ordinariamente denominados viajantes, naturalistas, etnógrafos, geógrafos, botânicos, zoólogos, cronistas, pintores, dentre tantos outros, além dos registros escritos, também realizaram coletas de materiais que viriam a enriquecer coleções de grandes museus enciclopédicos, principalmente da Europa e da América do Norte, assim como acervos de particulares.

Desta forma, temos um duplo registro produzido pelos viajantes: o material representado pelas coleções zoológicas e botânicas principalmente - e o bibliográfico, ou seja, os livros, artigos, cartas, ensaios etc., por eles redigidos. Esta parte bibliográfica é conhecida como Literatura de Viagem e ganha ampla repercussão durante o século XIX ao se tornar um dos meios mais populares de conhecimento das terras brasileiras por diferentes públicos nacionais e estrangeiros.

Atualmente, estas fontes são retomadas por variados estudiosos como aporte para a compreensão de realidades, muitas vezes, deixadas a parte por uma escrita centralizadora que, ao privilegiar estudos de grandes centros urbanos, marginaliza as interações que regiões periféricas tiveram com o período e que, mesmo deixadas a parte, também foram visitadas, narradas, descritas e estudadas.

Dentro deste quadro, destacamos a Amazônia Marajoara ${ }^{3}$, região que, apesar de pouco pesquisada em escritos de viajantes do século XIX, foi centro de interesse de

\footnotetext{
${ }^{1}$ Universidade Federal do Pará, Brasil.

${ }^{2}$ Universidade Federal do Pará, Brasil.

${ }^{3}$ Pacheco (2006) problematiza o termo "Ilha de Marajó", o qual reproduz uma visão homogênea sobre a complexa região marajoara, invisibilizando diversas populações de diferentes matrizes étnico-raciais e seus contatos interculturais. Assim, sem negar relações, mas atento a especificidades e pluralidades de viveres na Amazônia em determinados contextos geohistóricos, ele opta por termos como "Amazônia
} 
diversas expedições ao longo de sua história, destacando-se a literatura de viagem oitocentista. Na lista de muitos homens e raras mulheres ${ }^{4}$ que foi possível esquadrinhar, emerge Emilio A. Goeldi, Alfred Wallace, Príncipe Adalberto da Prússia, Daniel Kidder, Ferreira Penna, Henry Bates, Orville A. Derby, Paul Le Cointe, Antonio Baena, Louis e Elizabeth Agassiz, Charles Hartt, A. de Belmar, John Warren, entre outros.

No imenso rio de histórias registradas por estes viajantes sobre a Amazônia Marajoara, ganha destaque as muitas narrativas sobre a natureza da região. Fauna e Flora pululam para todos os lados dos escritos com seus simbolismos e características peculiares, chegando, muitas vezes, a suplantar descrições e situações de cidades, vilas, casas isoladas e seus moradores. Tal aspecto já deixa ver a força das relações entre humanos e não-humanos na literatura de viagem e os sentidos que ganham na especificidade de cada escritura.

De fato, importa dizer que em suas excursões, os viajantes passavam grande parte do tempo dentro de navios em traslados entre cidades. Apesar de fazerem algumas paradas para abastecimento ou embarque e desembarque de pessoas em vilas marajoaras, grande parte de seus relatos foram produzidos de dentro das embarcações ou de breves excursões às margens dos rios da região, durante paradas para aguardar a chegada da maré desejada para voltar a navegar. Assim, nestas idas e vindas, a paisagem principal descrita era composta por rios, matas e animais que viam, fato que explica sua predominância nos relatos.

Nos registros dos viajantes que singraram as águas marajoaras no correr do século XIX, a exuberância e variedade natural é sempre exaltada, as vezes em forma de poetizações dos deslumbrantes e luxuriantes elementos - adjetivos atribuídos por boa parte dos homens das letras às paisagens da região - sentiam acentuar sua proeminência por esta forma de expressão; ou em descrições mais puramente científicas, com longas exposições das características físicas dos animais, seus nomes científicos, peculiaridades, cores, entre outros.

Igualmente, emergem das folhas dos livros, histórias de grandes caçadas nas margens dos rios ou nos arredores das vilas e fazendas, narradas com tom de aventura e desbravamento e que se revestem com um ar colossal, poético e mesmo pictórico. Deste ponto de vista, percebemos que o viajante assume várias posições: a) escritor focado no

Marajoara", "Marajós", "Marajó do Campos" e "Marajó das Florestas”. Tais elaborações partilharemos ao longo do artigo.

${ }^{4}$ Sobre mulheres viajantes no século XIX, conferir (Leite, 2000; Sartori, 2015). 
trabalho de classificação, descrição e coleta de espécimes; b) poeta deslumbrado com a grandiosidade natural da região; c) caçador, desbravador e homem de grandes aventuras vividas nas matas amazônicas. Tudo isso, atravessado pelas zonas fronteiras da cultura local e estrangeira em simbiose. Precisamos, desse modo, estar atentos aos poderosos esforços daqueles que seguravam a pena para ordenar o mundo marajoara e "incorporálo progressivamente na órbita do Estado" (Montero, 2006: 25).

Nestes quadros, as práticas descritas pelos viajantes permitem problematizar de que ângulo observaram a Amazônia Marajoara, quais concepções de mundo estavam por trás das narrativas, quais expectativas e quais conflitos revelaram ou silenciaram em seus trânsitos pelas diversas paisagens físicas da região.

É preciso destacar a grande potencialidade dos estudos com literatura de viagem no que concerne a possibilidade que estas fontes criam para compreendermos distintas relações estabelecidas com humanos e não-humanos. Como já evidenciamos em outro trabalho, muitas das descrições permitem analisarmos conflitos de percepções (Araújo \& Pacheco, 2015) entre habitantes locais em deslocamento, principalmente índios tapuias, negros, mestiços e brancos pobres, com os viajantes.

Frente ao exposto, podemos defender também a ideia de os livros de viagens serem uma construção polissêmica, ou seja, escritos por muitas mãos. Ao ingressarem em uma jornada pela região amazônica, os viajantes constantemente estavam em contato com interlocutores locais para melhor arranjar as viagens. Tais interlocutores iam desde membros da elite local - que cediam estadia em fazendas na região, mapas, sugestões de roteiros de acordo com o interesse da viagem, provisões, etc. - até índios e negros que acompanhavam os excursionistas e cediam valiosas informações sobre cartografia, animais, plantas, acontecimentos, superstições, entre outras, que eram tomadas e narradas nos livros, sendo muitas vezes até suprimida sua verdadeira fonte em prol de uma escrita creditada somente ao viajante. Assim, ao narrarem suas sagas pelo vasto mundo marajoara os viajantes não registravam somente suas visões de mundo, mas também a daqueles que os acompanhavam, revelando escrituras polifônicas e interculturais.

Diante disso, neste trabalho objetivamos analisar representações forjadas pelos viajantes em seus livros sobre a fauna marajoara. Procuramos identificar como são narrados os encontros com animais da região, atentos para descrições, concepções e 
imaginações nas relações estabelecidas pelos viajantes com agentes não-humanos que povoam e fazem as paisagens da região.

Tais objetivos surgem a luz dos questionamentos: Quais narrativas são produzidas pelos viajantes a respeito da fauna local? Que aspectos da relação humanoanimal são revelados a partir destas narrativas de viagem? Antes de respondermos a tais questionamentos, é necessário fazermos algumas ponderações acerca das compreensões que nos guiam sobre a região marajoara e sobre a literatura de viagem.

\section{Entre os dois Marajós: Teias e Diferenças}

A região marajoara pode melhor ser melhor situada e entendida em seus aspectos humanos e não-humanos que envolvem dimensões geográficas, geopolítica, econômicas e socioculturais. Ultrapassando a concepção de ilha, a região é composta por inúmeras outras ínsulas que conformam o imenso arquipélago. Como exemplo temos as ilhas Mexiana e a Caviana, que no século XIX foram visitadas pelo naturalista britânico Wallace. Oscar Leal, jornalista e viajante carioca que esteve no Pará em 1886, em seu livro Viagem a um país de selvagens (2012) defende tal geopolítica e comenta que a região marajoara

[...] longe de ser uma ilha, como quase todas as geografias afirmam, é simplesmente um dos maiores arquipélagos do globo. Conta cerca de 2 mil e tantas ilhas separadas por canais e formando um conjunto isolado completamente da terra firme, pelo canal do Tajipuru e pelos dois grandes rios (Leal, 2012: 184-5).

Já no que concerne ao aspecto sociocultural, para mais do que uma visão historicamente forjada que acabou por silenciar identidades, culturas e patrimônios africanos, indígenas e afroindígenas (Pacheco, 2012) em prol de uma representação simplista e totalizante dos Marajós, parte importante da Amazônia, a região foi formada a partir de relações interculturais, resultando em trocas interétnicas, de saberes e fazeres no decorrer do tempo.

Os Marajós foram construídos mediante uma série de encontros culturais perpetrados por indígenas, europeus e africanos em vários períodos históricos. Esta construção ocorreu tanto por intermédio de relações conflituosas, quanto por relações de barganha. $\mathrm{O}$ choque entre as diferentes etnias permitiu o intercâmbio de saberes e fazeres ritualísticos, bem como de cosmologias conflitantes (Silva, 2013: 19). 
Assim, na perspectiva geográfica e geopolítica, desde os tempos de colonização, os Marajós vivem na dinâmica de uma zona de contato (Pratt, 1999), inicialmente dos encontros, guerras e trocas culturais de nações indígenas, que habitavam a região, entre si, depois com diferentes povos europeus e mais tarde (século XVII em diante) com a inserção da mão de obra de negros traficados do continente Africanos e vendidos em portos do Maranhão e do Grão-Pará. Não podemos deixar de questionar a forma esquemática como foram concebidos os dois lados da região pela historiografia oficial: o Marajó dos Campos como terra da presença negra e o Marajó das Florestas como terra da presença indígena. Entretanto, é preciso quebrar essa classificação para sondar os mundos cruzados tecidos por indígenas e negros na reconstrução das paisagens locais como contínuas construções geoculturais.

Certamente não podemos apagar as distinções, pois os dois Marajós em conexão, possuem geografias e histórias específicas. No Marajó dos Campos, situado no nordeste da região, tem-se o prevalecimento de grandes campos alagadiços e a cultura do gado domina. Já o Marajó das Florestas, localizado a sul e sudoeste, com densas áreas de florestas, esteve, ao longo de sua trajetória, economicamente voltado para a extração de drogas do sertão, da borracha, da madeira, do palmito, do açaí, para citar os principais.

Emílio Goeldi, no alvorecer do século XX, relata que

Se traçarmos uma diagonal que, partindo da foz do rio Cajuúna, vai até a embocadura do rio Atuá, teremos Marajó obliquamente divididas em duas partes quase iguais, uma a nordeste, outra a sudoeste. A primeira metade é caracterizada pelas imensas planícies dos campos e das savanas, onde existe uma criação de gado bastante considerável, se bem que tecnicamente imperfeita; na metade sudoeste, em que predomina a floresta virgem, tipicamente amazônica, expande-se, sob o signo de Aquário, a colheita da borracha (1902: 371).

Tal acentuação se torna importante se levarmos em conta as rotas traçadas e os locais visitados pelos viajantes. Na maioria dos casos estudados, os excursionistas pontuam a região marajoara como um caminho, um ponto de passagem e de abastecimento. O roteiro mais comum entre eles é aquele que se inicia em Belém e de lá toma-se um navio para subir rio acima até cidades como Santarém, Tefé, Manaus, ou mesmo para outros países, como o Peru. 
Na rota obrigatória para quem subia no século XIX o rio Amazonas, ganhava destaque, na Amazônia Marajoara, as vilas de Breves e Gurupá, ambas no Marajó das Florestas, locais que os navios faziam parada obrigatória. A primeira era porto de abastecimento de madeira utilizada, quando já havia sido introduzido o navio a vapor na região, para alimentar as caldeiras; e a segunda, era entreposto fiscal do Rio Amazonas, local onde se realizavam vistorias de produtos e, no caso de estrangeiros, a verificação de seus passaportes e autorizações de viagem. Nestes locais, costumeiramente os viajantes passavam parte da manhã ou da noite, o que lhes possibilitava incursões pelas vilas e registros dos modos de vida e de aspectos gerais da localidade, estando contempladas, neste caso, as interações estabelecidas entre humanos e não-humanos.

Paralelamente a este roteiro, também tinham aqueles que dedicavam mais tempo nas excursões pela região marajoara, visitando não somente as vilas da região de florestas, mais singrando pela região de campos, rota contrária para quem vai subir o Amazonas a partir de Belém. Neste cenário, ganham importância vilas como Soure e Salvaterra, já nos casos das florestas, além das já mencionadas vilas de Breves e Gurupá, duas outras povoações aparecem com proeminência: Jungcal e Cajueiro.

Assim perpetrados, a classificação enquanto Marajó dos Campos e Marajó das Florestas ganha importância, pois, sendo as rotas acima descritas as mais comuns adotadas, determinados aspectos referentes a região serão mais ordinários em detrimentos de outros. Em outras palavras, as narrativas que se fazem sobre a rota no rio Amazonas irão primar majoritariamente por descrições dos aspectos da realidade vivida por seus autores, ou seja, descrições de florestas; por outro lado, aqueles que foram para as zonas de campos, descreverão a região com esta paisagem.

Um exemplo do que mapeamos pode ser verificado no livro Brasil: Amazonas - Xingu (2002) de Príncipe Adalberto da Prússia, viajante que esteve no Brasil na década de 1840. Diz ele:

Marajó é ainda conhecida por ter todas as espécies de animais que a Província do Pará tem e, o que mais nos interessava, que os numerosos rebanhos de gado nos campos na sua parte norte, diz-se que atraem mais onças do que encontram em todas as cercanias, enquanto nos grandes charcos no seu centro os crocodilos devem pulular. (Prússia, 2002: 227-8) 
O predomínio da criação do gado no Marajó dos Campos parecia quebrar-se nos escritos dos viajantes quando faziam questão de enfatizar a presença e o fascínio que as onças exerciam entre os estrangeiros em trânsito. Já as regiões mais centrais, onde a geografia é composta majoritariamente por rios e lagos, era território dos crocodilos.

Feitas as devidas ponderações acerca dos dois Marajós em teias e diferenças, partiremos agora para um breve debate concernente à metodologia de pesquisa e o modo como lidamos com a literatura de viagem na compreensão da fauna regional.

\section{Percursos da Investigação}

A busca por relatos de viagem sobre a região marajoara no século XIX fez trilharmos por bibliotecas, repositórios digitais, periódicos da época, arquivos, cartas e documentos. Neste processo, ganhou destaque o livro de Rubens Borba de Moraes Bibliographia Brasiliana (2010), no qual o autor faz um grande levantamento de relatos de viagem produzidos sobre o Brasil de 1500 a 1900.

$\mathrm{Na}$ pesquisa, delimitamos nosso campo a partir de três aspectos principais para investigação: o recorte temporal; obras com narrativas sobre a região marajoara; e os livros escritos nos idiomas que dominamos, a saber, português, inglês, francês, espanhol e, em alguns raros casos, alemão. Somente em uma das situações recorremos a uma narrativa em italiano devido sua singular importância, para a qual contamos com o auxílio da tradução.

Pelos esforços da pesquisa centrarem-se temporalmente no século XIX, este foi nosso primeiro marco para a seleção. Investigamos nas 636 páginas que compõem cada tomo do livro de Rubens Borba de Moraes, obras publicadas durante o oitocentos. Da mesma maneira, ao encontrarmos uma referência, buscávamos identificar menções as terras marajoaras, suas vilas entre campos ou florestas. Fomos auxiliados nesta procura, em grande parte, pelo próprio título dos livros. O nome da obra pode dizer muito sobre seu conteúdo, em livros de viagem do século XIX, ordinalmente existe uma menção a seu recorte temporal ou geográfico. 
Um exemplo do que digo são os livros do médico alemão Robert AvéLallemant. Reise durch Süd-Brasilien im jahre 1858 (1859) $)^{5}$, que narra a viagem do autor pelas províncias do Rio Grande do Sul, Santa Catarina e São Paulo, por outro lado, Reise durch Nord-Brasilien im jahre $1859(1860)^{6}$, descreve as aventuras de AvéLallemant pelas províncias do norte do Brasil. Assim, é possível compreender a partir do que é designado nos títulos determinados aspectos do que será veiculado.

De fato, não podemos olvidar de dois fatores que também atentamos. $\mathrm{O}$ primeiro é a possibilidade de uma narrativa de viagem ter sido produzida em uma época e publicada posteriormente. O segundo é o fato de poder existir títulos de livros nos quais não estão contempladas as temáticas de nosso interesse, mas que em seu conteúdo a trazem. Portanto, apenas naqueles casos nos quais o nome da obra possibilitava excluí-la como fonte possível, ou seja, não se tratando de livros de viagem com temática amazônica, como é o caso do livro de Avé-Lallemant sobre o sul do Brasil, é que não os investigamos individualmente. Da mesma forma, todos os livros com os quais interagimos, buscamos confirmar a data da viagem a qual o relato se dedica com o intuito de certificarmo-nos da validade de sua utilização.

Contamos ainda com um segundo aliado para fazermos a seleção dos textos que comporiam nossas fontes: o próprio Rubens Borba de Moraes. Na segunda edição de seu livro, são acrescentados comentários sobre as obras, sua temática geral, dados sobre os autores, a época em que foi empreendida a expedição, locais por onde transitaram, entre outros aspectos que facilitaram a localização das informações desejadas.

Como exemplo, podemos citar uma pequena parte dos comentários que faz sobre Príncipe Adalberto da Prússia.

O príncipe Adalberto e sua comitiva chegaram ao Rio de Janeiro em 1842 e fizeram várias viagens pelos arredores (Nova Friburgo, Macaé, Campos). Do Rio embarcaram para o Pará, e dali subiram o Amazonas até o Xingu, percorrendo o rio por trechos até então desconhecidos do homem branco. [...] (Moraes, 2010: 39).

\footnotetext{
${ }^{5}$ Em tradução livre: Viagem através do sul do Brasil no ano de 1858. Esta obra foi traduzida pra o português e dividida em diversos volumes.

${ }^{6}$ Em tradução livre: Viagem através do norte do Brasil no ano de 1859. Esta obra também possui versão traduzida para o português, contudo, apenas seu segundo volume intitulado No Rio Amazonas, 1859 (1980), de publicação da Editora da Universidade de São Paulo.
} 
Desta forma, encontra-se uma possível referência, considerando que, como comenta Rubens Borba de Moraes, Adalberto subiu o rio Amazonas, trajeto que obrigatoriamente leva-os a passar pela região marajoara.

Alguns livros, como é o caso do de Mirian Moreira Leite Livros de viagem 1803/1900 (1997), disponibilizam em seus conteúdos listas de viajantes. No caso do livro supracitado, por ter uma abrangência das viagens a nível nacional, mas um recorte temporal delimitado (século XIX) é disponibilizada uma listagem de viajantes que passaram por alguma região do Brasil no referido período. Na publicação ainda são informados dados como a naturalidade do viajante, o ano de seu nascimento e falecimento, o período em que esteve em território nacional, a idade com que o naturalista chegou ao Brasil, sua profissão, o livro que foi consultado para a obtenção dos dados e a instituição que financiou a expedição.

Por sua vez, João Meirelles Filho em seu livro Grandes Expedições à Amazônia Brasileira 1500-1930 (2009), tem um enfoque mais regional, mas com um recorte temporal mais amplo. O autor constrói uma relação de viajantes organizada cronologicamente, destacando o nome do viajante, a duração de sua expedição, data de nascimento e falecimento do expedicionário, bem como algum comentário.

De posse das referências encontradas, empreendemos viagens na busca dos livros, ganhando destaque os repositórios digitais, como o Internet Archive e o Gallica, este último a versão online da Biblioteca Nacional da França. Excursionamos também por bibliotecas e arquivos públicos como a Domingos Soares Ferreira Penna, do Museu Paraense Emílio Goeldi, e o Arquivo Público do Estado do Pará, além de termos adquirido publicações em livrarias e sebos locais, ganhando destaque a Livraria do Senado Federal Brasileiro, que editou a coleção O Brasil Visto por Estrangeiros e criou a série especial Viajantes, na qual publica diversos livros de viajantes que se aventuraram pelo Brasil no século XIX.

A metodologia escolhida para análise dos textos adquiridos se baseia no trabalho de Mary Anne Junqueira (2009), atenta ao caráter plural e diversificado da literatura de viagem. Assim, a busca por uma homogeneidade tanto em seu conteúdo, quanto nas maneiras de investigação por meio destas fontes torna-se tarefa ardilosa. Entretanto, a autora postula alguns cuidados que o pesquisador deve ter ao aproximar-se deste tipo de fonte: 
[...] conferir o "lugar de enunciação" e o universo cultural do viajante; avaliar o período em que se escreveu o texto (durante ou após a jornada); a forma como foi elaborado o relato (narrativa, memória, cartas, diário etc.); e quando se publicou o texto, se for o caso. Mas, antes de qualquer coisa, devemos nos perguntar quem é o escritor do relato ou "quem ele quer ser" (Junqueira, 2009: 47).

No que se refere ao segundo e terceiro aspecto - a saber: a forma como foi elaborado o relato e quando se publicou o texto - estão ligados a outras duas concepções as quais também chama atenção a autora. A primeira diz respeito ao fato de que todo relato pressupõe um leitor, o qual pode ser tanto o próprio viajante - este é o caso do diário, escrito como suporte de lembranças que serão recuperadas em momentos futuros - ou um público mais específico - a exemplo de livros e publicações especializadas em determinados assuntos que tinham características próprias voltadas para estes leitores - ou mesmo um público mais amplo cada vez mais crescente no século XIX - como os romances e textos de jornais baseados nos relatos.

Neste mesmo sentido, o momento em que foi publicado o texto revela pistas sobre sua construção na medida em que sua escrita pode ter tido lugar ainda durante a excursão ou imediatamente após a viagem ou meses, até mesmo anos, após a expedição. Neste caso, o escritor se prende a memória para relatar os acontecimentos, produzindo o que a autora chama de memória de viagem. Além do mais, caso o texto tenha sido publicado, ainda há possibilidade de revisão do trabalho final, tanto pelo próprio viajante, quando por terceiros, para adequar o conteúdo ao público ao qual se voltará.

Em caminho similar, seguimos também as orientações de A. Cellard, que em trabalho intitulado Análise documental (2008), postula cinco dimensões para serem analisadas na pesquisa: a) o contexto, fazendo referência ao período histórico e ao universo sócio-político em que foi produzido o documento; b) o(s) autor(es), propondo um estudo sobre a pessoa que narra os fatos, seus interesses, motivações, objetivos etc.; c) a autenticidade e a confiabilidade do texto, onde se deve avaliar a qualidade da informação transmitida, estar atento ao fato de a escrita de um texto poder ter sido feita por um terceiro, que muitas vezes necessitava traduzir e interpretar passagens ou às vezes decifrar escritas quase ilegíveis; d) a natureza do texto, ou seja, se ele é um documento de natureza teológica, médica, jurídica, fato que pode influenciar também no público ao qual o mesmo era destinado, visto que só aqueles com certa iniciação conseguiriam encontrar sentido no texto; e) por fim, os conceitos-chave e a lógica interna do texto, requerendo do pesquisador estar atento a códigos espalhados pela 
escrita para identificar aspectos inerentes ao meio sociocultural no qual estava inserida a produção da narrativa, é o caso de gírias, regionalismos, maneiras de escrever, jargão profissional, entre outros.

Considerando o caráter plural dos textos, as questões propostas por Junqueira (2009) e as dimensões a serem analisadas de A. Cellard (2008) ganham importância para alcançarmos os objetivos ao qual nos propomos aqui, pois através delas é possível questionar os objetivos da viagem, o lugar de enunciação, a quem se destinava os relatos e, desta forma, melhor compreender as imagens forjadas pelos viajantes acerca da fauna marajoara, bem como das relações humano-animal.

\section{Narrativas e práticas da fauna marajoara}

Por sua posição geográfica estratégica, na foz do rio Amazonas, os Marajós se tornaram passagem obrigatória para todos aqueles que pela Amazônia pretendem se aventurar. Além, por ser detentora de uma rica fauna e flora, a região tornou-se um singular campo de estudos, quer em análises do tempo presente, quer em momentos pretéritos.

Como já enfatizamos anteriormente, durante o século XIX inúmeros foram os viajantes que para o Brasil vieram, aventuraram-se de norte a sul e registraram suas impressões em seus diários e livros. Junto dessa empreitada, estes homens da ciência recolheram rico material da fauna, da flora e dos modos de vida das populações amazônicas para guarnecerem museus estrangeiros e coleções de particulares que se interessavam pela temática.

Submergindo neste mundo bibliográfico produzido pelos viajantes, podemos notar que existia um intenso interesse pela fauna amazônica, merecendo destaque três momentos que ensejavam nas narrativas: descrições de caçadas, descrições científicas e descrições da paisagem. Tomaremos estas três temáticas para analisar a recorrência da fauna nos relatos.

As caçadas são os momentos que mais ensejam as descrições sobre os animais na região marajoara. Esta prática podia ter lugar tanto quando os viajantes estavam nas viagens de barco, quanto em vilas ou fazendas da região. 
No primeiro caso, prevalece uma relação de subsistência, onde apesar de os navios serem sempre guarnecidos com provisões para todo o período da viagem, eram frequentes as buscas por alimento fresco, quer em idas às margens ou em tentativas de atirar em algum animal de dentro do barco. As análises sobre as ocorrências de animais confundem-se em parte com os estudos sobre os hábitos alimentares destes sujeitos em aventura pelo vasto mundo marajoara.

Príncipe Adalberto da Prússia relata a prática de sempre manter uma espingarda carregada para estas ocasiões.

Pela manhã e à tarde era de regra conservar pelo menos uma espingarda carregada, por que quase sempre se oferecia oportunidade de matar algo; o Conde Bismark, por exemplo, matou hoje um japu e um belo pica-pau, do tamanho de nossa gralha; vimos também lindas araras-azuis, com o papo amarelo e asas encarnadas e azuis, e a maior parte voando aos pares por cima de nós; os guaribas, contrariamente aos seus hábitos, chamaram muito cedo nossa atenção com os seus uivos na floresta à nossa esquerda (Prússia, 2002: 242).

O viajante ainda relata a incitação à caça que as aves da Amazônia Marajoara causavam.

[...] [nossos olhos] passeavam de um lado para o outro acompanhando o vôo dos numerosos e para nós em parte novos pássaros aquáticos, sobretudo aquelas grandes gaivotas brancas, uma espécie de garça branca e variedades com cabeça cor de carne, que incitavam nossa paixão pela caça, animando o ar e a água, tendo o Conde de Bismark morto um mergulhão (um pássaro entre um pato e um ganso) e o Conde Oriolla uma grande ave de rapina branca (Idem: 244).

Importa dizer, neste caso, a singularidade dos relatos de Príncipe Adalberto da Prússia. Amante do saber, sem possuir formação nas ciências naturais, o principal objetivo desse viajante ao atravessar variadas paisagens brasileiras era percorrer os mares, desejo que trazia desde a infância. Assim, constantemente suas narrativas se revestem de um caráter aventureiro, deixando de lado análises mais propriamente científicas, não sendo encontrados, por exemplo, os nomes científicos dos animais por ele descrito, preferindo tomar informações cedidas por seus companheiros de viagem, em sua maioria índios tapuias e negros. Desta forma, a presença da fauna em suas descrições vai quase sempre aparecer ligadas à busca por alimento ou oportunidade de uma aventura de caça. 
Já nas vilas ou fazendas da região marajoara, por outro lado, as caçadas nem sempre estavam ligadas à subsistência, mas em grande parte a um controle populacional. Nestes casos, pode estar vinculada principalmente ao fato de animais como onças e jacarés atacarem as criações dos fazendeiros, ou, por outro lado, para uma manutenção mais efetiva do controle de cabeças de gado cavalar.

No primeiro caso, tomamos os relatos de Alfred Russel Wallace, naturalista britânico que na segunda metade do século XIX excursionou pela região marajoara, tendo permanecido principalmente entre as ilhas Mexiana e Caviana, na costa noroeste do arquipélago, e que narra uma caçada a jacarés empreendida pelo administrador local em companhia de diversos índios e negros com o objetivo de controlar o grande número destes animais que frequentemente atacavam as reses dos fazendeiros.

Alguns negros entraram na água, levando compridas varas, com as quais empurravam os animais para o lado, onde outros os esperavam com arpões e laços. De quando em quando, um laço era jogado sobre as cabeças dos jacarés, ou, se algum já tivesse sido arpoado, outro laço era arremessado para prendê-lo, quer pela cabeça, quer pela cauda, e assim é fácil mente puxado para a praia, pelos esforços conjugados de dez ou de doze homens.

Outro laço ainda é jogado, se assim for preciso, para ter o animal preso em ambas as extremidades.

$\mathrm{Na}$ ocasião de ser arrastado para fora da água, um negro, armado de machado, cautelosamente dele se aproxima, e, com um golpe seguro corta-lhe a cauda, tornando completamente inútil a formidável defesa do bicho, e, desfechando-lhe logo outro golpe, sobre o pescoço, separa a cabeça do tronco. Este é assim deixado ali no chão.

Em seguida, começa a perseguição a outro animal, que, pela mesma forma, dentro de pouco tempo, fica reduzido a idênticas condições.

Acontecia, às vezes, romper-se o laço, ou o arpão desprender-se, e os negros tinham então que patinhar na água, no meio dos ferozes animais, de maneira horrivelmente arriscada.

Tinham aqueles bichos dez a dezoito pés de comprimento, alguns chegando mesmo a vinte, com enormes e disformes cabeças e horríveis fiadas de longas e aguçadas presas.

Depois de muitos deles já se acharem em terra, uns mortos, outros ainda morrendo, foram em seguida abertos, para extrair-se-lhes a banha, acumulada em torno das entranhas, em grande quantidade, e que era retirada e colocada sobre os couros dos menores, couros esses tirados especialmente para tal propósito.

Há outra espécie menor, aqui chamada "jacaretinga", cuja carne é a preferida para se comer, sendo muito mais delicada do que a das espécies maiores.

Após ter matado uns doze ou quinze jacarés, o administrador e os seus homens foram dali para outro lago, situado a curta distância, onde tais bichos ainda são encontrados em maior número, e, até ao escurecer, já haviam matado cerca de 50.

No dia seguinte, foram mortos ainda mais uns 20 ou 30.

Em seguida, iniciou-se a extração da banha dos que foram mortos na véspera (Wallace, 2004: 139-40). 
A caçada aos jacarés para proteger as reses, garantir alimentação e extração da banha para a comercialização era intensa no século XIX, de acordo com narrativas de Wallace, lembrando que "atitudes de simpatia com animais variam segundo as tradições culturais" (Descola, 1998: 23). De acordo com o viajante, certa vez em poucos dias foram mortos mais de mil jacarés. Nestas narrativas os animais assumem posição de competidores, disputado com os donos de fazendas os recursos da região. Interessa visualizar o uso dado aos animais depois de mortos, ocorrendo a extração de sua banha e couro, sendo, entretanto, preferida a carne do jacaretinga para o consumo.

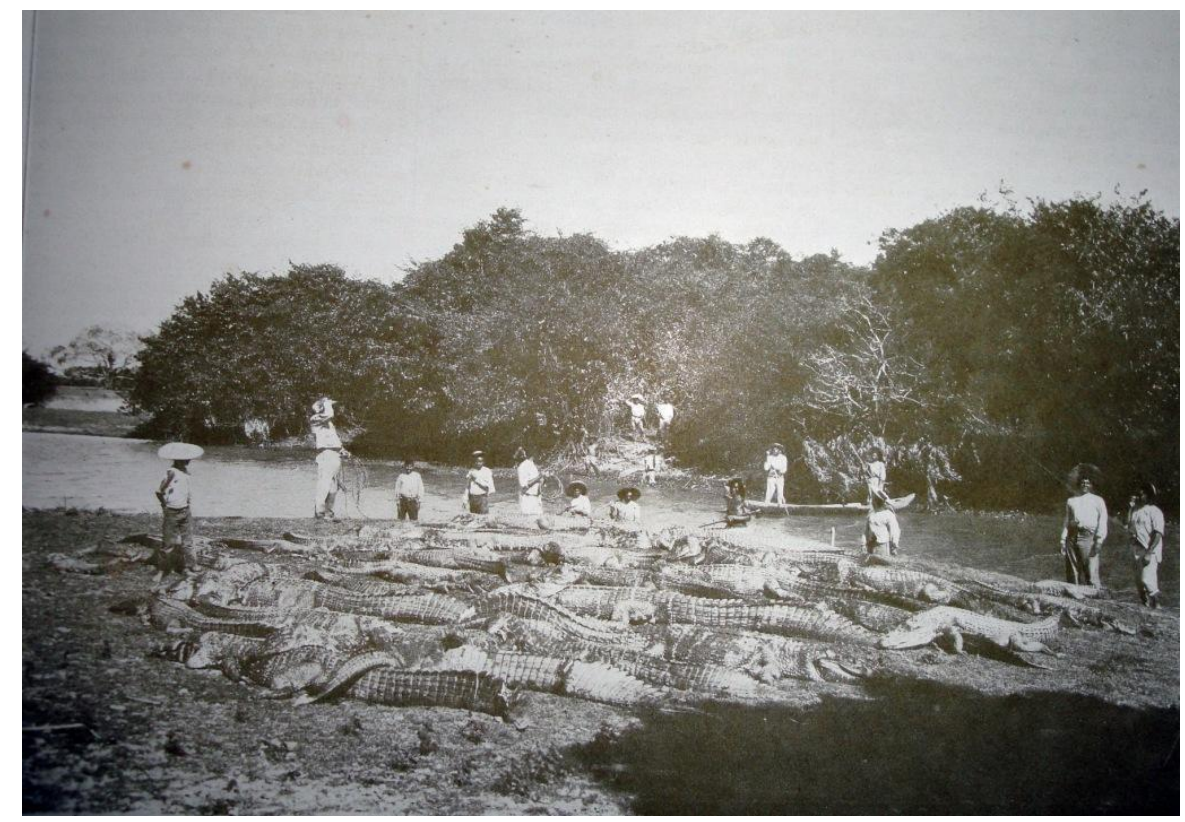

Figura 1: Matança de Jacarés (Fonte: Álbum do Pará - 1908: 163)

O controle populacional também era empreendido no gado cavalar. A criação do gado, sendo uma das principais atividades da região marajoara, sempre aparece nas descrições. Sobre este aspecto, José Coelho da Gama e Abreu, o Barão de Marajó, um importante político brasileiro, que desenvolveu diversas pesquisas sobre a região amazônica, narra em seu livro As Regiões Amazônicas - Estudos Chorographicos dos Estados do Gram Pará e Amazonas (1992), o excessivo crescimento do número de cavalos selvagens na região que disputavam os recursos com o gado dos fazendeiros. Para controlar a disputa, eram empreendidas caçadas contra os referidos animais da floresta. 
O gado cavallar, cuja introdução na ilha deve ser da mesma epocha que a do gado vaccum, tomou uns pouco de annos tal desenvolvimento que se tornou um inconveniente, pois subindo a um numero que se calcúla duplo do gado bovino, tornado selvagem, devastaram os campos, devorando os pastos já insufficiente para o gado vaccun.

Então aproveitaram-se differentes especuladores pedindo authorisação, que lhes foi concedida, para comprar e matar milhares de éguas para lhe aproveitar as pelles e as crinas. O resultado d'esta enorme matança, que subiu a muitas dezenas de milhares, foi que abandonados os corpos á simples acção do sol, ficou por tal maneira corrompida a athmosphera, que se tornou impossível a approximação d'aquellas localidades. A este estado corrupto attribuem os habitantes da ilha o ter apparecido alli uma moléstia que, atacando a raça cavallar, affectanto os membros posteriores, os matava; a esta moléstia deram elles o nome de quebra-bunda, a qual ainda dura e tem acabado com o gado cavallar até o ponto de ser já insufficiente para o trabalho, impondo grandes sacrifícios aos fazendeiros que os mandavam vir de outros Estados (Marajó, 1992: 309).

Evidencia-se nestas passagens o uso comercial do animal. Apenas seu couro e crina eram aproveitados, o primeiro para produção de utensílios como roupas e sapatos, o segundo para produção de pincéis, principalmente. $\mathrm{O}$ interesse comercial proporcionar mais pasto ao gado vacum, cuja carne abastecia as cidades da região, inclusive Belém, a capital do estado do Pará - leva a matanças dos animais, que, por conta dos abandonos das carcaças dos animais a céu aberto, levou ao surgimento de doenças que afetaram o gado cavalar e mais tarde o vacum, provocando a perda de enormes cifras.

Paralelamente a estas caçadas e matanças ensejadas por interesses comerciais ou busca por aventuras, as ocorrências dos relatos de animais aparecem nas descrições científicas dos viajantes. Estas são mais recorrentes em textos de naturalistas, zoólogos, botânicos ou geógrafos que vinha para a região amazônica com propósitos de estudos nas suas áreas e ensejavam buscas por espécimes nas matas. Este é geralmente o caso das expedições científicas como as de Wallace e Henry Bates e a do casal Louis e Elizabeth Agassiz.

Henry Walter Bates foi um naturalista britânico que esteve no Brasil por onze anos, de 1848 a 1859, veio na companhia de Alfred Russel Wallace, mas se separou deste e empreendeu suas próprias excursões pela região. Bates veio com objetivo claro de recolher material zoológico e botânico para o Museu de História Natural de Londres, a quem remeteu mais 14.000 espécimes, a maior parte delas novas, sendo grande número de insetos. Era recorrente assim estes homens e uma mulher de ciência ensejarem também caçadas na busca destes espécimes. 
Bates, em uma das experiências de viagem, narra uma das caçadas de coleta que faz na região marajoara, onde logo após sair do rio Uituquara, todos foram à margem, a tripulação para pescar e ele e seu companheiro empreenderam uma rápida excursão pela terra para fins de coleta.

[...] meu companheiro conseguiu acertar num anacá (Derotypus coronatus), uma das mais belas espécies da família dos papagaios. Sua cor é verde, e ele tem uma espécie de topete de penas vermelhas orladas de azul na parte de trás da cabeça, a qual ele levanta e abaixa à vontade. O anacá é o único papagaio da América que tem alguma semelhança com a cacatua da Austrália. É encontrado em todas as terras baixas da região amazônica, mas não é comum a sua presença em outros lugares. [...] Os homens da tripulação voltaram trazendo uma grande quantidade de peixe; surpreendeu-me a enorme variedade de espécies, entre as quais predominava um Loricaria de $30 \mathrm{cms}$ de comprimento, cujo corpo é inteiramente envolto numa armadura óssea. Esse peixe é encontrado com abundância nas rasouras, em determinadas épocas (Bates, 1979: 97).

Chama atenção no relato do naturalista que ele não se preocupa em narrar somente o fato acontecido, ele busca complementar as informações com o nome científico das espécies, suas características físicas, peculiaridades, sua dispersão, taxonomia e quando possível, elaborava um registro.

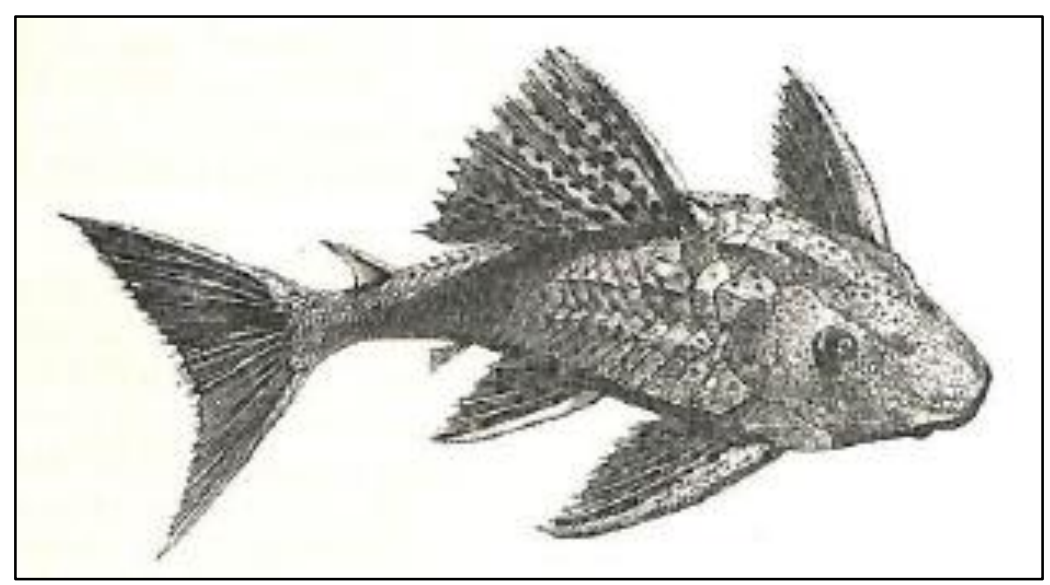

Figura 2: Peixe Acari (Loricaria duodecimalis)

(Fonte: Bates, 1979: 98)

O casal Agassiz, por sua vez, em seu livro Viagem ao Brasil 1865-1866 (2000), no qual narra suas excursões pelo território nacional na Expedição Thayer, também desenvolveram extenso trabalho de coleta de materiais. É importante dizer que Louis Agassiz é mais conhecido por suas teorias de defesa do hoje chamado racismo 
científico, ao posicionar-se contra a miscigenação de raças, contudo, este zoólogo suíço paralelamente se empenhou na coleta de materiais, principalmente da fauna amazônica.

Em uma carta enviada ao Sr. Pimenta Bueno e publicada em seu livro, Louis Agassiz narra, por ocasião de sua passagem pela região marajoara, as coletas que empreendeu naquela região.

\begin{abstract}
Meu caro amigo, Estou extenuado de fadiga, mas não quero ir me repousar sem lhe haver escrito umas palavras. Ontem, à tarde, conseguimos obter 27 espécies de peixes em Gurupá, e, esta manhã, 57 em Porto da Moz, ao todo 84 espécies em menos de onze horas, e, no número delas há 51 novas. É maravilhoso. Não pude mais pôr em ordem o que me trazem à medida que vem chegando; e quanto a obter desenhos coloridos de tudo, nem se pode cuidar mais disso, a menos que, na volta, passemos uma semana inteira aqui. Todo seu, L. Agassiz (Agassiz, 2000: 173)
\end{abstract}

O objetivo da realização destas coletas, classificação e ordenação era, além de formar as grandes coleções, também desenvolver a prática das ciências naturais. Era necessário (re)conhecer o mundo amazônico, que até então ainda estava desvinculado das amarras do protecionismo português. Assim, era preciso conhecer, estudar, classificar e coletar espécimes.

De fato, é preciso comentar que existiam interesses pessoais envolvidos nestas coletas. Ao excursionarem para a região amazônica, além das coletas para os grandes museus europeus e norte-americanos, que financiavam grande parte das viagens, estes homens de letras também objetivavam ganhar fama e fazer fortuna. Para ensejarem tal propósito eram enviados espécimes para renomadas casas de leilões especializadas na venda destes artigos para grandes barões que estavam dispostos a pagar pequenas fortunas para terem um exemplar destes "exóticos" animais em suas residências. Carla Lima (2014) comenta que, sobre tal fato, a capital inglesa possuía um intenso movimento de negócios ligados à venda de espécimes: leilões, agentes de vendas, lojas especializadas, entre outros.

Pode-se compreender melhor tal realidade por meio do negociante Samuel Stevens: especializado na venda e no leilão de objetos de história natural, conduziu com eficácia seu negócio (um esquema de venda pelo qual os clientes poderiam escolher o espécime de sua preferência através de um sistema semelhante a um cardápio de restaurante ou uma lista de livros) e apoiou muitos naturalistas que coletavam em várias partes do mundo. Entre estes, Bates e Wallace certamente foram seus mais talentosos coletores (Lima, 2014: 22). 
Assim, mesmo para estes homens da ciência, a região amazônica e em especial sua fauna, representava uma grande oportunidade de enriquecimento e busca pela fama.

Por fim, a presença dos animais nas narrativas de viagem também era frequente quando estes profissionais visitavam as vilas e descreviam a paisagem. Ganha importância aqui os relatos dos viajantes Frank e Fred, no livro de Thomas W. Knox The Boy Travellers in South America (1886), no qual os dois autores excursionaram para as vilas de Soure e Salvaterra e relatam uma prática diária:

P. S.-Our account of Para would be incomplete without an allusion to snakes. In many houses they have snakes of the boa-constrictor family - of the kind we saw on the Amazon - to keep the place clear of rats and mice. They do their work very well, and live on terms of quiet friendship with the biped inhabitants. At Sourre we saw the household snake coiled up in a corner very much as we might see a cat in a New England dwelling; when we manifested a curiosity to look at it one of the servants took the reptile by the neck and held it up to full view until we declared ourselves satisfied with the inspection. The creature did not'seem at all angry at his treatment, for as soon as he was released he returned to his corner and resumed his nap.

We have just visited Monkey Joe's establishment, which is devoted to the sale of monkeys, parrots, snakes, and other Amazonian live-stock. We made no purchases, in spite of the tempting offers at low prices, as we have found one monkey quite as much as we wish to carry in our travels. Outside of the shop a man was standing with a barrel by his side ; when we left the place he followed us a short distance and emptied his barrel on the ground. He was a snakemerchant, with a choice selection of rat-killers that he vainly urged us to buy. We left him and his wares; as he was perfectly at home among the wriggling serpents, and had no fear of them, he was unable to understand why we departed so suddenly ${ }^{7 "}$ F. and F." (Knox, 1886: 348).

Neste relado percebemos uma relação mutua entre humano e animal, onde a cobra foi domesticada e substituía o papel do que hoje pertencem aos pets, mais do que isso, a cobra desempenhava um papel crucial na casa: exterminar os ratos e aqui vale

\footnotetext{
${ }^{7}$ Tradução livre do autor: "P.S. - nossa conta do Pará estaria incompleta sem uma alusão as cobras. Em muitas casas eles tem cobras da família da jiboia - do tipo que nós vimos no Amazonas - para manter o local limpo de ratos e ratazanas. Elas fazem seu trabalho muito bem, vivem em termos de completa amizade com os habitantes bípedes. Em Soure nós vimos a cobra doméstica enrolada em um canto, tanto quanto nós podemos ver um gato em uma habitação em New England; quando nós manifestamos a curiosidade de olhar elas, um dos criados pegou o réptil pelo pescoço e a segurou para visualização completa até nós nos declararmos satisfeitos com a inspeção. A criatura não pareceu de toda raiva com o seu tratamento, pois assim que ele foi libertado, voltou para seu canto e retomou a sua sesta.

Nós tínhamos acabado de visitar o estabelecimento do Macaco Joe, que é devotado a vender macacos, papagaios, cobras, e outros animais da Amazônia. Nós não fizemos comprar, apesar das ofertas tentadoras de preços baixos, como nós tínhamos encontrado um macaco, tanto quanto nós desejamos carregar em nossas viagens. Do lado de fora da loja, um homem estava em pé com um barril ao seu lado; quando nós deixamos o local ele nos seguiu por uma pequena distância e descarregou seu barril no chão. Ele era um comerciante de cobras, com uma seleção escolhida de matadoras de ratos que ele em vão nos incentivou a comprar. Nós deixamos ele e suas mercadorias; como ele estava perfeitamente em casa entre as serpentes que se contorciam, e não tinha medo delas, ele era incapaz de entender por que nós partimos tão repentinamente "F. and F."
} 
destacar a comparação do autor, quando comenta que cobras são tão recorrentes quanto gatos em New England, animal que por sua vez também é conhecido por caçar ratos.

Paralelamente a esta percepção, notamos o uso comercial dos animais, inicialmente no estabelecimento de Macaco Joe, que vendia animais da região como pets e mais ainda com o comerciante de cobras, que se dedicava à prática da venda do réptil como "matadoras de ratos".

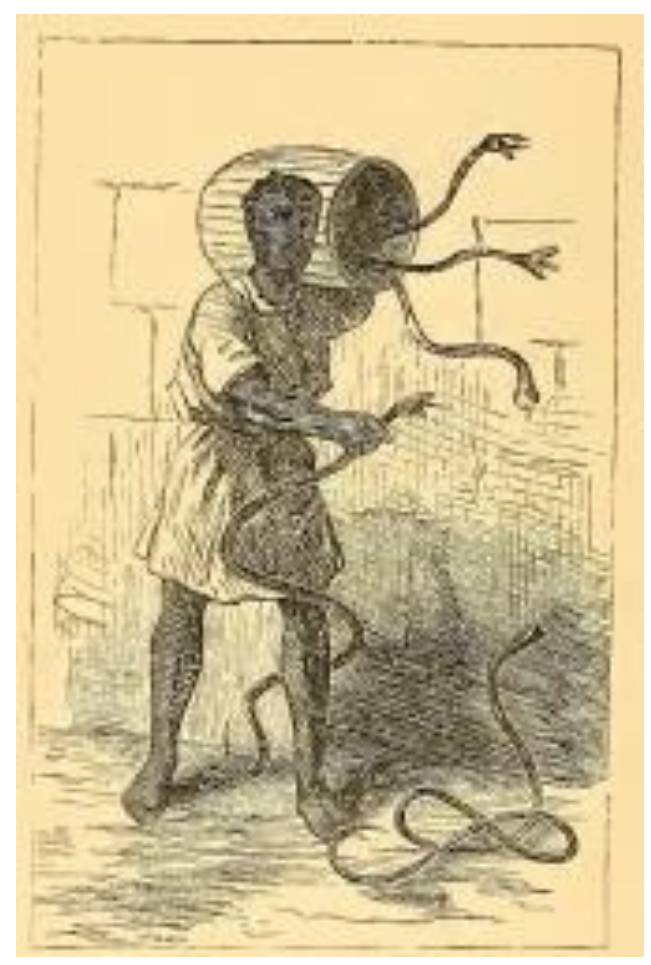

Figura 3: Comerciante de cobras (Fonte: Knox, 1886: 348)

\section{Considerações Finais}

Ao entrarem em contato com a fauna amazônica, merecendo especial destaque aqui a marajoara, os viajantes sentiam despertar interesses, desejos e sentidos múltiplos, fato que leva a diferentes posicionamentos, quando se colocam diante de pássaros, cobras, jacarés, insetos.

A fauna desperta o desejo pela caça, como narra Príncipe Adalberto da Prússia, mas também está ali para ser conhecida, catalogada, ordenada, coletada e exposta, como nos casos de Henry Bates, Alfred Russel Wallace e o casal Agassiz. Por outro lado, ela 
faz parte da vida cotidiana das vilas, os habitantes locais harmonizam-se com os animais, os adotam e lhes dão lugares em suas casas.

Os animais estavam nos sentidos destes homens, eles se deleitavam ao descreverem cenas pictóricas com belas aves voando em um por do sol dourado, ou mesmo quando não estavam presentes visualmente, eles sabiam que estes estavam lá, pois ouviam seus sons, como atesta Wallace "Os ruídos da vida animal, na verdade, nunca se interrompem aqui" (Wallace, 2004: 142). Estes animais estavam no paladar, eram caçados e comidos, como afirma Bates sobre o peixe acari "Sua carne é um pouco seca, mas de sabor razoável” (Bates, 1979: 97). A fauna estava no olfato, no pitiú do peixe, no cheiro da tartaruga sendo cozida com sua couraça que levou ao desespero do Príncipe Adalberto da Prússia “[...] devido a seu fedor excedendo tudo que se possa imaginar e a espessa fumaça mefítica [...]” (Prússia, 2002: 239).

É trabalho árduo tentar dar conta da riqueza da fauna marajoara e suas relações com os viajantes apenas em um artigo acadêmico de caráter preliminar. Apesar das dificuldades e limites interpretativos da interconexão humano e não-humano, as narrativas revelam interações, interesses, necessidades e visões específicas dos homens e uma mulher de ciência no contato com a região e a diversidade e singularidade de sua fauna.

Atravessados pelo olhar científico do século XIX e a ânsia por catalogar, classificar, nominar e normalizar plantas e animais aos padrões ocidentais (Pratt, 1999), mas se contaminando com o simbolismo dos modos de ser e viver no mundo marajoara, os viajantes tornaram-se agentes históricos de mediação e tradução cultural (Montero, 2006). Com isso, contribuíram para a elaboração de um modo de ver, sentir e pensar a região, disseminado em escala planetária. 


\section{Referências}

AGASSIZ, Jean Louis Rodolph. AGASSIZ, Elizabeth Cary. Viagem ao Brasil 1865-1866. Tradução e notas de Edgar Süssekind de Mendonça. Brasília: Senado Federal, Conselho Editorial, 2000.

ARAÚJO, Lucas Monteiro de. Os Marajós em Relatos: Narrativas Museais de Viajantes no século XIX. Trabalho de Conclusão de Curso, Instituto de Ciências da Arte, Universidade Federal do Pará, 2014.

BARREIRO, J. C. Imaginário e viajantes no Brasil do século XIX: cultura e cotidiano, tradição e resistência. São Paulo: Editora UNESP, 2002.

BATES, Henry Walter. Um naturalista no rio Amazonas. Belo Horizonte: editora Itatiaia. São Paulo: editora da Universidade de São Paulo. 1979.

CANCLINI, Néstor García. Diferentes, desiguais e desconectados: mapas da interculturalidade. Tradução Luiz Sérgio Henrique. 3. Ed. Rio de Janeiro: Editora UFRJ, 2009.

CONSTANTINO, Núcia Santoro de (org). Relatos de viagem como fontes a história. Porto Alegre: EdPUCRS, 2012.

DESCOLA, Philippe. Estrutura ou Sentimento: a relação com o animal na Amazônia. Mana, v. 4, no 1, p. 23-45, 1998.

GOELDI, Emilio A. Maravilhas da Natureza na Ilha de Marajó. In. Boletim do Museu Paraense de História Natural e Ethnographia. Tomo III. F 1-4. Typographia de Alfredo Silva \& comp. Pará - Brasil, 1902.

GUIMARÃES, Leandro Belinaso. WORTMANN, Maria Lucia Castagna. Passando a limpo a Amazônia através da literatura de viagem: ensinando modos de ver. REP - Revista Espaço Pedagógico, v. 17, n. 2, Passo Fundo, p. 306-318, jul./dez. 2010,

JUNQUEIRA, Mary Anne. Elementos para uma discussão metodológica dos relatos de viagem como fonte para o historiador. Junqueira, Mary Anne. Franco, Stella Maris Scatena (Orgs.). Cadernos de Seminários de Pesquisa, v. 3, p. 44-61, 2009.

KNOX, Thomas W. The boy travellers in South America. New York: Harper \& Brothers, 1886.

KURY, Lorelai B. A sereia amazônica dos Agassiz: zoologia e racismo na Viagem ao Brasil. Revista Brasileira de História, São Paulo, v. 21, nº 41, p. 157-172, 2001.

LEITE, Mírian Moreira. Mulheres Viajantes no Século XIX. Cadernos PAGU (15), Campinas, p. 129-143, 2000.

. Livros de viagem: 1803-1900. Rio de Janeiro: Editora da UFRJ, 1997.

LIMA, Carla Oliveira de. A experiência de campo de Alfred Russel Wallace na Amazônia oitocentista: viagem, ciência e interações. Tese de Doutorado, Casa de Oswaldo Cruz - Fiocruz. 2014.

MONTERO, Paula (Org.). Deus na Aldeia: missionários, índios e mediação cultural, São Paulo, Globo, 2006.

MARAJÓ, Barão de. As regiões amazônicas: Estudos Chorographicos dos Estados do Gram Pará e Amazonas. Belém: Secult, 1992.

MORAES, Rubens Borba de. Bibliographia Brasiliana:

Livros Raros sobre o Brasil Publicados desde 1504 até 1900 e Obras de Autores Brasileiros do Período Colonial. São Paulo: Edusp, 2010.

PACHECO, Agenor Sarraf. A Conquista do Ocidente Marajoara: índios, portugueses e religiosos em reinvenções históricas. In: SCHAAN, Denise Pahl, MARTINS, Cristiane Pires (Orgs.) Muito além dos campos: arqueologia e história na Amazônia Marajoara. Belém: GKNORONHA, 2010, p. 13-32. À Margem dos "Marajós": cotidiano, memórias e imagens da "cidade-floresta" Melgaço-PA. Belém: Paka-Tatu, 2006 . As Áfricas nos Marajós: visões, fugas e redes de contatos. In. SCHAAN, Denise Pahl, MARTINS, Cristiane Pires (Orgs.) Muito além dos campos: arqueologia e história na Amazônia Marajoara. Belém: GKNORONHA, 2010, p. 33-71.

. Cosmologias Afroindígenas na Amazônia Marajoara. Projeto História, São Paulo, n. 44, p. 197-226, jun. 2012. 
; SILVA, Jaddson Luiz Sousa. Nas Margens do Patrimônio Marajoara. Anais Eletrônicos do XXVII Simpósio Nacional de História da ANPUH, 2013. v. 01, p. 01-18.

PRATT, Mary Louise. Os olhos do império: relatos de viagem e transculturação. Bauru: EDUSC. 1999.

PRÚSSIA, Adalberto Príncipe da. Brasil: Amazônia-Xingu. Tradução de Eduardo de Lima e Castro. - Brasília: Senado Federal, Conselho Editorial, 2002.

SÁ-SILVA, Jackson Ronie. ALMEIDA, Cristóvão Domingos de. GUINDANI, Joel Felipe. Pesquisa documental: pistas teóricas e metodológicas. Revista Brasileira de História \& Ciências Sociais v.1, p. 1-15, 2009.

SARTORI, Maria Ester de Siqueira Rosin. Diário de uma Mulher Viajante do Século XIX: a memória perpetuada na palavra escrita. Anais do XXVIII Simpósio Nacional de História, Florianópolis-SC, julho de 2015, p. 1-19.

WALLACE, Alfred Russel. Viagens pelo Amazonas e Rio Negro. Notas de Basílio de Magalhães. Brasília: Senado Federal, Conselho Editorial, 2004.

Recebido em: 29/10/2016.

Aprovado em: 01/12/2016. 